\title{
Neumoescroto secundario a un neumotórax a tensión bilateral
}

\author{
Di Capua Sacoto C, Bahilo Mateu P, Ramírez Backhaus M, Gimeno Argente V, \\ Pontones Moreno JL, Jiménez Cruz JF.
}

Servicio de Urología. Hospital Universitario La Fe. Valencia.

Actas Urol Esp. 2008;32(7):756-758

\section{RESUMEN}

NEUMOESCROTO SECUNDARIO A UN NEUMOTÓRAX A TENSIÓN BILATERAL

Presentamos un caso clínico de neumoescroto secundario a un neumotórax a tensión bilateral de gran tamaño. A pesar de que el neumoescroto es una entidad clínica poco frecuente que generalmente se resuelve con tratamiento conservador, puede ser sintoma de un proceso grave y potencialmente mortal. El tratamiento del neumoescroto estará encaminado a tratar la causa que lo produjo.

Palabras clave: Neumoescroto. Neumotórax. Complicaciones.

\section{ABSTRACT \\ PNEUMOSCROTUM SECONDARY TO BILATERAL TENSION PNEUMOTHORAX}

We present a case of pneumoscrotum due to bilateral tension pneumothorax. Although the pneumoescrotum is an uncommon and light disease it can be a symptom of a liFe threatening pathology. The treatment of the pnemoescrotum is ethiological. It is necessary to treat the specific disease responsible of the pneumoescrotum.

Keywords: Pneumoscrotum. Pneumotorax. Complications.

$\mathrm{S}$ define neumoescroto como la presencia de gas dentro del contenido de la bolsa escrotal. La etiología del mismo suelen ser procesos infecciosos, traumáticos, y hernias.

El neumoescroto es una entidad clínica poco frecuente. La primera referencia bibliográfica data de $1912^{1}$, desde entonces hay descritos menos de 100 casos en la literatura.

En cuanto su manejo, puede ser conservador cuando lo encuadramos en un cuadro clínico benigno o quirúrgico cuando se trate de un proceso grave. Deberemos, por tanto prestar atención al contexto clínico, en el que se desencadene.

\section{CASO CLÍNICO}

Se trata de un varón de 26 años, politraumatizado tras un accidente de tráfico que fue atendido en el servicio de urgencias de nuestro centro. A su llegada, el paciente ventilaba de forma espontánea con una saturación de oxígeno al 85\%, una frecuencia cardiaca de 98 pulsaciones por minuto y la exploración neurológica revelaba una escala de coma de
Glasgow de 4/15. A la inspección se objetivaba un tubo de drenaje toráxico colocado por el médico del SAMUR ante la sospecha de un neumotórax a tensión post-traumático. Durante su valoración en la puerta de urgencias se objetivo como el tamaño de la bolsa escrotal aumentaba de forma progresiva (Figs. 1 y 2). Por este motivo se solicitó la valoración urgente por parte del servicio de urología.

Siguiendo el protocolo del servicio orgánico de urgencias para pacientes politraumatizados se solicito analítica completa, se cruzó y reservaron dos concentrados de hematíes y se solicitó una tomografía axial computerizada (TC) craneal-torazo-abdóminopélvica.

En la TC se objetivaba un hematoma frontopariteal derecho y occipital, hemoneumotórax a tensión, bilateral, múltiples fracturas costales (costillas 6, 7, 8) así como un enfisema subcutáneo que disecaba la pared torácica de forma bilateral y el retroperitoneo hasta llegar al canal inguinal y al escroto (Fig. 3). Los testículos y estructuras epididimarias eran normales. 


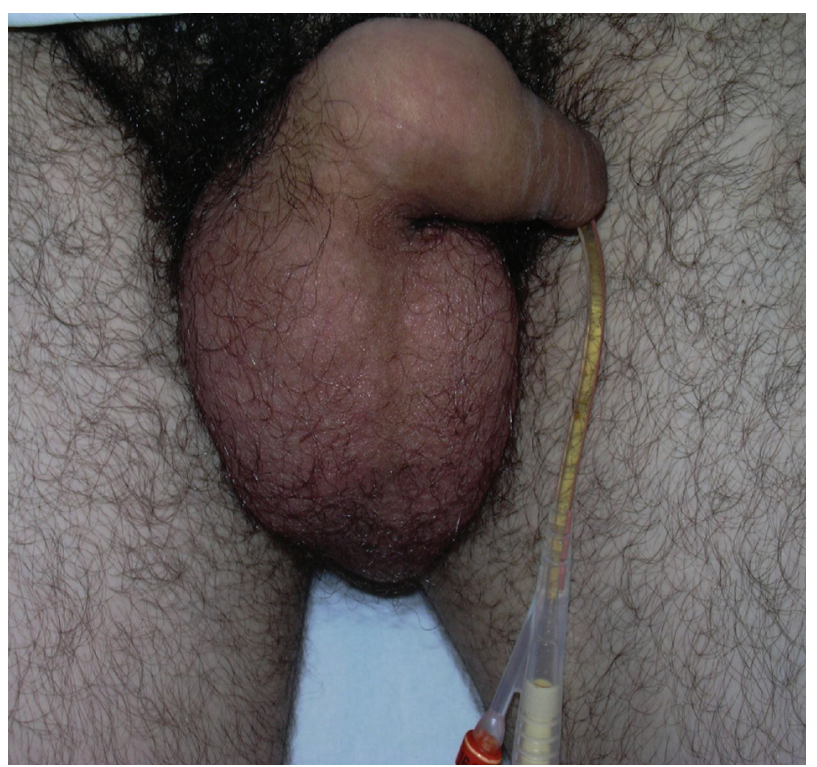

FIGURA 1. Se observa a la llegada a puertas de urgencias el aumento de volumen de la bolsa escrotal.

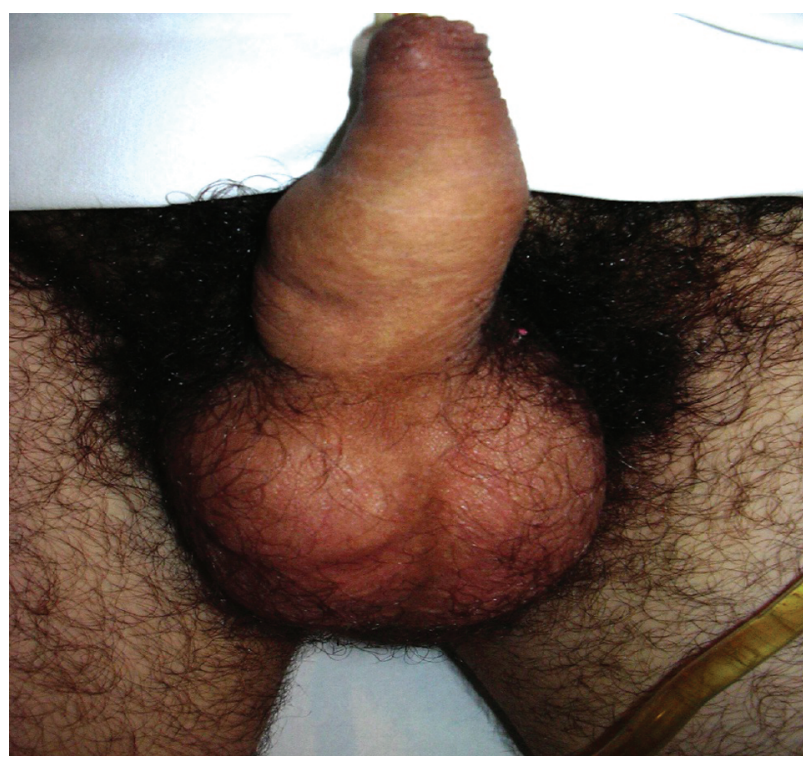

FIGURA 2. Se observa como el aire que se encuentra en el neumoescroto diseca los cuerpo cavernosos formando un neumopene.

Ante estos hallazgos el paciente fue trasladado a la unidad de cuidados intensivos previa colocación de dos tubos de drenaje torácicos. El neumoescroto se decidió manejar de manera conservadora colocando un suspensorio testicular.

Los neurocirujanos deciden que el hematoma frontoparietal y occipital que se objetiva en la TC dadas su extensión y escasa repercusión clínica realizar manejo conservador observando su reabsorción al cabo de 35 días.

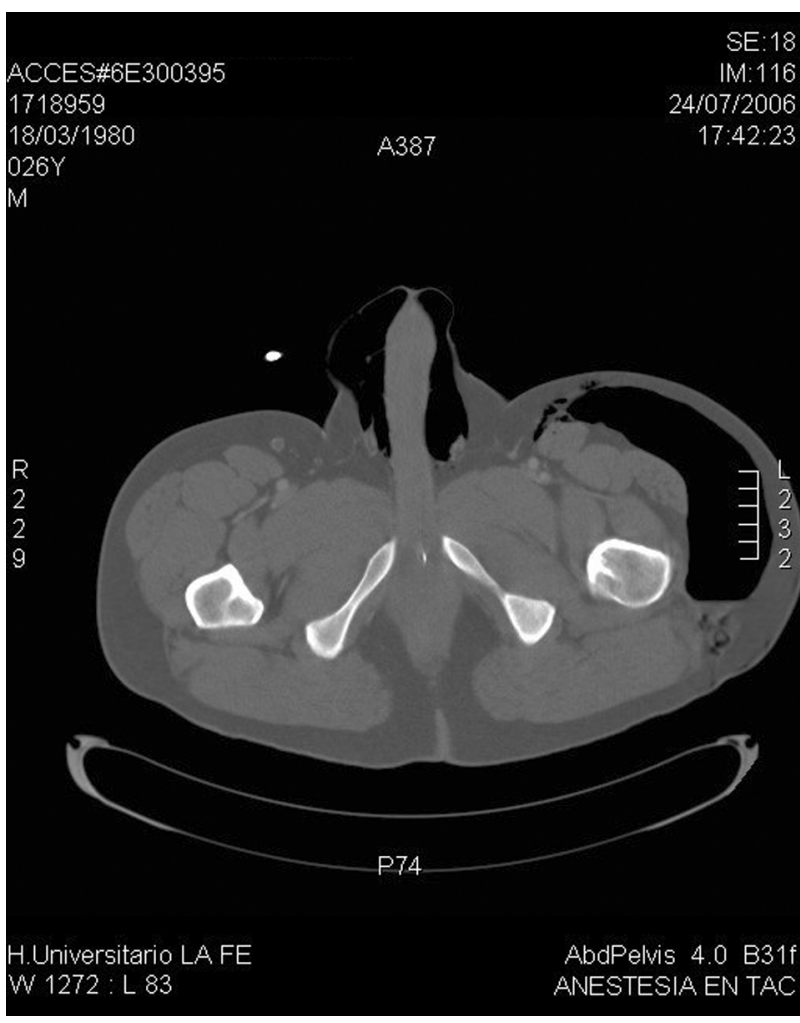

FIGURA 3. Se visualiza como el aire ha bajado por la pared lateral y retroperitoneo; entra a la bolsa escrotal visualizándose el aire dentro de la misma.

Durante su estancia hospitalaria el paciente padeció dos infecciones respiratorias que retrasaron la retirada de la respiración asistida hasta 21 días tras el accidente. El neumoescroto se resolvió de forma espontánea a los 12 días. El paciente fue dado de alta al mes del politraumatismo sin secuelas neurológicas.

En un control ambulatorio a los 6 meses el paciente refería, tan sólo, una leve debilidad del miembro superior izquierdo, sin sintomatología respiratoria ni urológica alguna. Se realizó una ecografía doppler escrotal que no relevo hallazgos significativos de interés.

\section{DISCUSIÓN}

Se han descrito varias teorías para explicar la llegada de aire a la bolsa escrotal.

Uno de ellas postula que la ruptura alveolar facilita el paso de aire a través de las fascias vasculares del pulmón pasando posteriormente al mediastino y desde allí por el tejido celular subcutáneo llegaría al abdomen y al escroto ${ }^{2}$. Otros piensan que el aire diseca un plano más profundo que el tejido subcu- 
táneo, la fascia de escarpa ${ }^{3}$. Otra de las vías descritas es el paso de aire a través del hiato diagramático, hasta alcanzar el espacio pararenal y por el retroperitoneo hasta el canal inguinal y desde allí siguiendo la fascia espermática al escroto ${ }^{4,5,7}$.

$\mathrm{El}$ neumoescroto generalmente es un proceso de características benignas, pero muchas veces esta asociado a enfermedades potencialmente mortales por lo que una detallada anamnesis y examen físico son fundamentales en el manejo del mismo ${ }^{5}$.

La mayor parte de los casos de neumoescroto descritos en la literatura médica tienen como origen del aire una fuente lejana al escroto. El enfisema escrotal está muchas veces asociado a la realización de procedimientos diagnósticos y/o terapéuticos. Los pulmones y los órganos digestivos con contenido aéreo, son los orígenes más frecuentes. La colonoscopia es una de las técnicas a las que se ha asociado el neumoescroto con mayor frecuencia ${ }^{7,8}$

Las pruebas de imagen son importantes, tanto la radiografía simple torácica y abdominal como la TC de pelvis, abdomen y tórax. Generalmente con esto será suficiente para averiguar el origen ${ }^{9,10}$.

El tratamiento del neumoescroto debe ir encaminado a solucionar la enfermedad subyacente por la que se produjo. Sin embargo algunos autores han descrito la extracción del aire por drenajes, esta medida actualmente ha sido desaconsejada. El tratamiento sintomático del neumoescroto incluyen medidas de reposo, suspensorio testicular y analgésicos para evitar el dolor.

\section{REFERENCIAS}

1. Keyes EL. Two cases of pneumoscrotum following nephrectomy. Am J Urol. 1912;8(4):68-70.

2. Millmond SH, Goldman SM. Pneumoscrotum after spontaneous pneumothorax with air leak. J Urol 1991;145(6):1271-1272.

3. Heimbach D, Hofmockel G, Wirth M, Frohmuller H. Pneumoscrotum. Case report and review of the literature. Urologe A. 1993;32 (6):503-506

4. Casey RG, Al-Dousari S, Murphy D, Power RE. Chest drain insertion may result in the acute scrotum. Scand J Urol Nephrol. 2006;40(1):78-79.

5. Watson HS, Klugo RC, Coffield KS. Pneumoscrtoum: report of two cases and review of mechanisms or its development. Urology. 1992;40(6):517-521.

6. Carlsen CU, Andreassen KH. Benign pneumoperitoneum and scrotal emphysema after colonoscopy. Ugeskr Laeger. 1992; 154(25):1785-1786.

7. Mateos Colino A, Golpe Gómez R, González Rodríguez A, Sousa Escandón A, González Uribarri C, Seirulo Salas M, Neumoescroto secundario a efisema subcutaneo masivo tras el drenaje de un neumotorax espontáneo. Actas Urol Esp. 2004:606609 .

8. Eisenman A, Veissler A. Subcutaneous emphysema as a complication of colonoscopy. Harefuah. 1991;121(1-2):15-17.

9. Meyers MA. Radiological features of the spread and localization of extraperitoneal gas and their relationship to its source. Radiology. 1974;111(1):17-26.

10. Mutlu S, Mustafa T, Bulent G, Sahin U. Pneumoscrotum following perineal trauma. European Journal of Radiology. 2003; 26-29.

Correspondencia autor: Dr. C. Di Capua Sacoto Servicio de Urología. Hospital Universitario la Fe. Avda. Campanar $n^{\circ} 21$ - 46009 Valencia Tel.: 963862700

E-mail autor: carlosdicapua@hotmail.com Información artículo: Nota Clínica

Trabajo recibido: enero 2007

Trabajo aceptado: febrero 2007 